\title{
Spasmodic torticollis following unilateral VIII nerve lesions: neck EMG modulation in response to vestibular stimuli
}

\author{
ADOLFO M BRONSTEIN, PETER RUDGE, ANDREW H BEECHEY \\ From the Medical Research Council Neuro-Otology Unit, Institute of Neurology, National Hospital, Queen \\ Square, London UK
}

SUMMARY Three patients with spasmodic torticollis following VIII nerve lesions (VIII-ST) underwent quantitative assessment of their sternomastoid EMG during vestibular (otolith and semicircular canal) stimulation. The results were compared with a normal control group and with six patients with idiopathic spasmodic torticollis (ST). Backwards tilt of the VIII-ST patients resulted in a marked increase in the EMG, especially in the more affected sternomastoid, whereas this manoeuvre did not have a significant effect in normal subjects, or had a variable effect in the ST group. These results suggest that those with torticollis following VIII nerve lesions are a distinct group. Since there was no relationship between the side of the VIII nerve lesion and the direction of the torticollis a direct aetiological link between the two is, however, unlikely. The unusual EMG/tilt responses are explained on the basis of peripheral imbalance of utricular signals (maximad in the supine position) in the presence of central deranged processing of information concerning head posture.

The CNS relies on visual, proprioceptive and vestibular information to generate appropriate output to the cervical muscles controlling head position. For this reason damage to peripheral or central vestibular pathways gives rise to serious derangements of head posture in animals and occasionally in man. ${ }^{1-4}$ These abnormal head postures, it must be stressed, do not show the massive EMG discharge which characterises the head deviation seen in spasmodic torticollis (ST) ${ }^{5}$ However, recently we presented data from patients with spasmodic torticollis who did not have a previous history of vestibular disease, showing that a significant proportion of them had abnormal vestibular function. ${ }^{6}$ In brief, caloric and rotational tests frequently disclosed as asymmetric vestibulo-ocular reflex, the slow component of the nystagmus being more active in the direction of the head (chin) deviation. Since there have been other reports on the association between spasmodic torticollis and vestibular

Address for reprint requests: Dr AM Bronstein, MRC NeuroOtology Unit, Institute of Neurology, the National Hospital for Nervous Diseases, Queen Square, London WCIN 3BG, UK.

Received 10 May 1986 and in revised form 30 July 1986. Accepted 1 August 1986 lesions ${ }^{7-10}$ we studied three patients in whom torticollis followed an insult to the vestibular system (VIII-ST) in an attempt to clarify a possible aetiological relationship between the two.

In addition to routine neuro-otological assessment neck EMG was recorded whilst various types of vestibular stimuli were delivered. It was expected that if there was a connection between the torticollis and the neuro-otological lesion some common clinical features should be present and the EMG activity from the dystonic muscles might be modulated by vestibular stimulation in a consistent way.

\section{Materials and methods}

\section{Case reports}

Case 1 A 57 year old man who, at the age of 24 , suddenly developed severe vertigo, unsteadiness, nausea, vomiting, tinnitus and hearing loss in the left ear. These symptoms settled over 24 hours. During the next 4 years he had occasional vertigo but more frequent feelings of unsteadiness and pulsion to the left. The tinnitus and hearing loss remained unchanged. At 37 years of age he noticed progressive weakness of the left leg. A left acoustic neuroma was removed at the age of 52 years and at the time the patient noticed that his head was rotated to the right.

On examination there was in addition to the deafness a 
left lower motor neuron facial weakness, moderate pyramidal weakness on the left and a mild ataxia bilaterally. The head was turned to the right due to tonic contraction of the left sternomastoid which was hypertrophied. The right splenius and the left trapezius were also hypertrophic though to a lesser degree.

Case 2 A 62 year old man who had suffered from chronic bronchitis for many years. Five years before being seen he had a single episode of headache in the right parietooccipital region following which he developed trigeminal neuralgia in the right cheek and jaw. This was partially controlled with carbamazepine and phenytoin. He occasionally had blurred or double vision and a vague sensation of dizziness and unsteadiness but did not report rotational vertigo or hearing troubles. In the year before assessment he noticed that the head involuntarily turned towards the left, especially on lying in bed.

On examination the right sternomastoid was moderately hypertrophic and there was a bilateral exophoria. Jerky torticollis to the left, which clearly increased in the supine position, was present. A CT scan showed the basilar artery looping into the right cerebello-pontine angle.

Case 3 A 52 year old man who, at the age of 15 , developed involuntary movements of the face in which he screwed up his eyes and twisted the corner of his mouth. At the age of 45 he suffered attacks of vertigo with right sided tinnitus and progressive hearing loss. A right vestibular neuronectomy was carried out. This operation abolished the vertigo and the facial movement but he had moderate hearing loss with tinnitus and right facial weakness; the latter resolved over two months. Six months after the operation he developed head turning towards the right associated with neck pain.

On examination he had right torticollis with hypertrophy of the left sternomastoid. Both splenii and the right trapezius were mildly hypertrophic. There was a mild right facial weakness more marked around the mouth than the eye and a mild right pyramidal weakness.

\section{Control groups}

Two groups of subjects were used as controls. The first consisted of six normal male subjects, aged between 21 and 55 years, and the second of six patients with idiopathic spasmodic torticollis. The latter group comprised three males and three females aged between 32 and 59 years, with no previous history of otological disease; two had previously undergone a full neurootological investigation and had the typical directional preponderance of vestibular nystagmus in the direction opposite to the chin deviation.

\section{Electro-myography}

Surface Beckman silver cup electrodes were used to record the EMG from the sternomastoid on both sides of the neck. Raw EMG was displayed on-line by means of an ink jet recorder and collected on magnetic tape for subsequent processing on a Fourier analyzer (Solartron 1200) which displayed the power spectra and calculated the energy dissipated by the signal (power in band between 10 and $500 \mathrm{~Hz}$ ) in volts ${ }^{2}$. The frequency limit of the system was either 313 or $625 \mathrm{~Hz}$ according to the tape speed used. The periods analysed were approximately $30 \mathrm{~s}$ and usually included 30 averages. The first 10 seconds of EMG after each new vestibular stimulus was applied was not analysed to allow for stabilisation of the recording. Abnormally high peaks of activity at $50 \mathrm{~Hz}$ were deducted from the total power because this was always correlated with clearly identifiable noise on the paper recordings.

\section{Vestibular stimulation}

Vestibular modulation of the neck EMG was studied in response to tilt with respect to gravity (otolith stimulation) and to horizontal rotation (semicircular canal stimulation). In order to obtain quantifiable body tilt a bi-axial gymbal was used; the patients sat on a chair which restrained their arms and pelvis. The trunk was strapped in with an " $X$ " shaped seat belt; the legs and feet were also fitted with belts. The head rested backwards and was fixed, when required, with a binaural clamp. The position of the chair was monitored with a potentiometer. The subjects were tilted backwards in steps of $30^{\circ}$ up to a maximum of $90^{\circ}$ in the sagittal plane with the head resting freely. Then the head was clamped and the patients tilted $45^{\circ}$ backwards-forwards (sagittal plane) and right-left (coronal plane). These displacements were smooth and slow; the subjects stayed in the new position for at least a minute before being moved again. The effect of vision upon the EMG was assessed by obtaining records with eyes open and closed.

Rotational stimuli were delivered in the dark with a revolving chair which rotated around the vertical axis at a constant acceleration of 2 to $3^{\circ} \mathrm{s}^{-2}$ up to a maximal velocity of $100 \%$ s. This velocity was then maintained for about 2 minutes during which the room lights were turned on and off for periods of about 45 seconds in order to assess the role of optokinetic stimulation. The procedure was carried out at least twice to the right and twice to the left resulting in a total constant acceleration duration in each direction of least $132 \mathrm{~s}$. During rotation the head was in contact with an occip-

Table 1 Clinical and neuro-otological summary

\begin{tabular}{|c|c|c|c|c|c|c|c|}
\hline & VIII lesion & $\begin{array}{l}\text { Torticollis } \\
\text { (chin) }\end{array}$ & $\begin{array}{l}\text { Spontaneous } \\
\text { nystagmus }\end{array}$ & $O K N$ & $S P$ & $\begin{array}{l}\text { Caloric } \\
\text { test }\end{array}$ & $\begin{array}{l}\text { Rotational } \\
\text { test }\end{array}$ \\
\hline Patient 1 & $\mathbf{L}$ & $\mathbf{R}$ & $2^{\circ} \mathrm{R}$ & R DP & \multirow{2}{*}{$\begin{array}{l}\text { Saccadic } \\
\mathbf{R}>\mathbf{L} \\
\text { Saccadic }\end{array}$} & \multirow{2}{*}{$\begin{array}{l}\text { L CP } \\
\text { R DP } \\
\text { R DP }\end{array}$} & R DP \\
\hline Patient 2 & $\mathbf{R}$ & $\mathbf{L}$ & Nil & R DP & & & $\begin{array}{l}\text { Not } \\
\text { available }\end{array}$ \\
\hline Patient 3 & $\mathbf{R}$ & $\mathbf{R}$ & Nil & Normal & Normal & $\begin{array}{l}\text { R CP } \\
\text { L DP }\end{array}$ & $\begin{array}{r}\text { Hypoactive } \\
\text { bilaterally }\end{array}$ \\
\hline
\end{tabular}

OKN = Optokinetic nystagmus

SP = Smooth pursuit

DP = Directional preponderance of nystagmus

$\mathrm{CP}=$ Canal paresis 
Table 2 Resting EMG*: sternomastoid

\begin{tabular}{|c|c|c|c|c|}
\hline $\begin{array}{l}N C \\
\text { ST } \\
\text { VIII-ST }\end{array}$ & $\begin{array}{l}= \\
= \\
=\end{array}$ & $\begin{array}{l}\text { Affected } \\
\text { Unaffected } \\
\text { Affected } \\
\text { Unaffected }\end{array}$ & $\begin{array}{l}\mathrm{n}=11 \\
\mathrm{n}=5 \\
\mathrm{n}=4 \\
\mathrm{n}=3 \\
\mathrm{n}=3\end{array}$ & $\begin{array}{l}1.03 \times 10^{-2} \text { SD } 1.86 \times 10^{-2} \\
1.27 \times 10^{-1} \text { SD } 9.82 \times 10^{-2} \\
3.48 \times 10^{-1} \text { SD } 3.79 \times 10^{-1} \\
1.06 \times 10^{-1} \text { SD } 8.43 \times 10^{-2} \\
1.71 \times 10^{-2} \text { SD } 2.04 \times 10^{-2}\end{array}$ \\
\hline
\end{tabular}

*Expressed as the ratio: resting EMG/EMG during forced

voluntary head turn. $\mathrm{NC}=$ normal controls. $\mathrm{ST}=$ idiopathic

spasmodic torticollis controls. $n=$ number of muscles satisfactorily

studied. Affected = more affected sternomastoid; contralateral to

the chin deviation. Unaffected = least affected sternomastoid;

ipsilateral to the chin deviation.

ital rest but was not clamped. The subjects were instructed to relax and keep their eyes open.

\section{Results}

A summary with the main clinical and neurootological findings of the VIII-ST patients is presented in table 1 . There was no consistent relationship between the side of the vestibular deficit and that of the torticollis. In cases 1 and 3 the neurootological findings, apart from the saccadic pursuit in the former, can be explained on the basis of the VIII nerve section. In contrast, in patient 2 the marked directional preponderance of caloric nystagmus in the direction opposite to that of the chin deviation is typical of idiopathic spasmodic torticollis; although there was no unequivocal indication of peripheral involvement in the vestibular tests, the patient's symptoms and the radiological findings provide good evidence of unilateral vestibular impairment.

The results of EMG while the subjects were sitting up relaxed with the head unrestrained are presented in table 2 . As expected these resting values, expressed as a proportion of maximal voluntary contraction, are increased in both patient groups by an order of magnitude. Owing to this difference in the resting EMG, it was necessary to normalise the data of all the subjects in order to compare the effects of vestibular stimu-
Table 4 EMG during tilt back and forward; head clamped

\begin{tabular}{llll}
\hline & & $45 B$ & $45 F$ \\
\hline NC & $\mathrm{n}=11$ & 1.02 SD 0.29 & 1.39 SD 0.75 \\
ST & & & \\
Affected & $\mathrm{n}=6$ & 3.17 SD 3.50 & 1.74 SD 1.97 \\
Unaffected & $\mathrm{n}=6$ & 1.07 SD 0.46 & 1.02 SD 0.57 \\
Patient 1 & & 8.93 & 7.25 \\
Affected & & 1.02 & 4.74 \\
Unaffected & & 2.97 & 0.79 \\
Patient 2 & & 2.83 & 3.31 \\
Affected & & 1.94 & 2.6 \\
Unaffected & & 1.53 & 2.59 \\
Patient 3 & & & \\
Affected & & & \\
Unaffected & & & \\
\hline
\end{tabular}

lation. Thus, for each tilt and rotation experiment the mean of all the EMG activity values in the upright, resting position was calculated for each individual muscle and subject and this was taken as basal value. The effects of tilt upon this basal value are shown in tables 3 to 5 . Two main difficulties were encountered during data analysis, namely that the VIII-ST group was small and that there were important individual variations within both patient groups. As the latter produced considerable skewing of the data, the medians and interquartile ranges were plotted to give a clearer picture of the trends present in all patient groups (fig 1).

The greatest difference between the three groups tested was found during backwards tilt with the head free. In normal subjects the effects were negligible but in the VIII-ST patients a marked increase of EMG activity usually occurred. This was related to the degree of tilt and was maximal in the muscle most affected clinically (fig 2). Two of the three patients were tested on more than one occasion with similar results. In no case did a spasmodic torticollis patient have a comparable enhancement of the EMG in the more affected muscle. On the contrary, two spasmodic torticollis patients had a significant reduction

Table $3 E M G^{*}$ during tilt backwards; head resting freely

\begin{tabular}{|c|c|c|c|c|}
\hline & & $30^{\circ}$ & $60^{\circ}$ & $90^{\circ}$ \\
\hline $\begin{array}{l}\text { NC } \\
\text { ST }\end{array}$ & $\mathrm{n}=11$ & 0.99 SD 0.19 & 1.04 SD 0.19 & $1 \cdot 11 \mathrm{SD} 0.38$ \\
\hline $\begin{array}{l}\text { Affected } \\
\text { Unaffected } \\
\text { Patient } 1\end{array}$ & $\begin{array}{l}n=6 \\
n=6\end{array}$ & $\begin{array}{l}0.64 \text { SD } 0.33 \\
1.02 \text { SD } 0.44\end{array}$ & $\begin{array}{l}0.64 \text { SD } 0.34 \\
1.44 \text { SD } 1.64\end{array}$ & $\begin{array}{l}0.93 \text { SD } 0.82 \\
1.98 \text { SD } 2.29\end{array}$ \\
\hline $\begin{array}{l}\text { Affected } \\
\text { Unaffected } \\
\text { Patient } 2\end{array}$ & & $\begin{array}{l}8 \cdot 27 \\
4 \cdot 27\end{array}$ & $\begin{array}{c}10 \cdot 13 \\
4 \cdot 5\end{array}$ & $\begin{array}{r}26.02 \\
5.87\end{array}$ \\
\hline $\begin{array}{l}\text { Affected } \\
\text { Unaffected } \\
\text { Patient } 3\end{array}$ & & $\begin{array}{l}3.63 \\
1.6\end{array}$ & $\begin{array}{l}3.76 \\
1.99\end{array}$ & $\begin{array}{l}3 \cdot 14 \\
3 \cdot 25\end{array}$ \\
\hline $\begin{array}{l}\text { Affected } \\
\text { Unaffected }\end{array}$ & & $\begin{array}{l}0.92 \\
0.04\end{array}$ & $\begin{array}{l}0.87 \\
0.06\end{array}$ & $\begin{array}{l}4 \cdot 13 \\
0.10\end{array}$ \\
\hline
\end{tabular}

${ }^{*}$ Expressed as a ratio: EMG during tilt/EMG at $0^{\circ}$ of tilt. 
Table 5 EMG during coronal tilt at $45^{\circ}$; head clamped

\begin{tabular}{llcl}
\hline & & Side down & Side up \\
\hline NC & $\mathrm{n}=11$ & 5.53 SD 9.36 & 3.71 SD 7.65 \\
ST & $\mathrm{n}=5$ & 10.73 SD 12.13 & 3.99 SD 7.53 \\
Affected & 1.29 SD 0.53 & 1.19 SD 0.20 \\
Unaffected & $\mathrm{n}=5$ & 5.15 & 0.29 \\
Patient 1 & & 1.09 & 0.13 \\
Affected & & 4.88 & 1.68 \\
Unaffected & & 2.10 & 1.67 \\
Patient 2 & & 4.40 & 24.12 \\
Affected & & 1.46 \\
Unaffected & & 1.39 & \\
Patient 3 & & & \\
Affected & & & \\
Unaffected & &
\end{tabular}

Side down = left sternomastoid during left tilt or right sternomastoid during right tilt. Side up $=$ left sternomastoid during right tilt or right sternomastoid during left tilt.

of muscle activity as they were tilted backwards (fig 3 ). Activity in the clinically less affected muscle activity was not altered by this manoeuvre in five of the six spasmodic torticollis patients.

During $45^{\circ}$ tilt backwards or forwards with the head clamped, neck EMG usually increased in the VIII-ST patients. This effect was also commonly seen in the spasmodic torticollis group but not in the normal control group. Since spasmodic torticollis patients did not show EMG enhancement during sagittal tilt with the head free it is impossible to say how much of this effect was due to the tilt and how much due to the forced fixation of the head. Eye opening or closure did not affect the sagittal tilting responses.

Tilt in the coronal plane also had to be carried out with the head clamped. During this experiment all groups produced a similar pattern of EMG responses. Thus when the subjects were tilted to the right it was mainly the right sternomastoid which was activated as if opposing the tendency of the head to turn pas- sively in that direction and vice versa on tilting to the left. This response was more prominent in both patient groups than in normal subjects and specially in the clinically more affected muscles. Although the subjects were encouraged to relax it is not clear whether this EMG modulation was the result of voluntary or involuntary activity.

During rotational tests on consistent modulation of the EMG was found in the normal subjects or the VIII-ST patients. Some spasmodic torticollis patients, however, did have a rotational modulation of their muscle activity. From what is known of the vestibuloocular and vestibulo-cervical reflexes, it is conceivable that during acceleration say to the right, the head would turn to the left. Thus, it was considered that EMG modulation consistent with stimulation of the horizontal semicircular canals occurred either when the muscle ipsilateral to the direction of the acceleration increased its discharge or the activity in the contralateral muscle diminished (table 6). If a change of $10 \%$ is considered significant a consistent EMG modulation occurred one in eight instances $(12 \%)$ in the normal subjects, one in six $(16 \%)$ in the VIII-ST cases and six in $11(55 \%)$ in the spasmodic torticollis patients. There was no systematic optokinetic modulation of the EMG in any group nor were there any consistent differences in the frequency content (power spectra) of the EMG in the various groups. Highest levels of activity were in the region between $50-90 \mathrm{~Hz}$ with minimal power beyond $200 \mathrm{~Hz}$.

\section{Discussion}

The possible existence of a link between spasmodic torticollis and the vestibular system has interested neurologists for a long time $e^{6-12}$ and; not infrequently, isolated cases of otogenic spasmodic tor-

Table 6 EMG* during horizontal rotation

\begin{tabular}{|c|c|c|c|c|}
\hline & & Ipsilateral & Contralateral & $\begin{array}{l}\text { Cases with corresponding } \\
\text { modulation of EMG }\end{array}$ \\
\hline $\begin{array}{l}\text { NC } \\
\text { ST }\end{array}$ & $\mathrm{n}=8$ & $1.08 \mathrm{SD} 0.21$ & $1 \cdot 16$ SD 0.28 & $1-(12 \%)$ \\
\hline $\begin{array}{l}\text { ST } \\
\text { Affected } \\
\text { Unaffected }\end{array}$ & $\begin{array}{l}\mathrm{n}=5 \\
\mathrm{n}=6\end{array}$ & $\begin{array}{l}1.23 \text { SD } 0.71 \\
1.13 \text { SD } 0.32\end{array}$ & $\begin{array}{l}1.02 \text { SD } 0.60 \\
1 \cdot 16 \text { SD } 0.42\end{array}$ & $\begin{array}{l}3-(60 \%) \\
3-(50 \%)\end{array}$ \\
\hline $\begin{array}{l}\text { Patient 1 } \\
\text { Affected } \\
\text { Unaffected }\end{array}$ & & $\begin{array}{l}1 \cdot 20 \\
0.77\end{array}$ & $\begin{array}{l}0.33 \\
1.31\end{array}$ & $\begin{array}{l}\text { Yes - }(33 \%) \\
\text { No }\end{array}$ \\
\hline $\begin{array}{l}\text { Patient } 2 \\
\text { Affected } \\
\text { Unaffected } \\
\text { Patient } 3\end{array}$ & & $\begin{array}{l}0.46 \\
0.93\end{array}$ & $\begin{array}{l}0.73 \\
1.56\end{array}$ & $\begin{array}{l}\text { No } \\
\text { No }\end{array}$ \\
\hline $\begin{array}{l}\text { Affected } \\
\text { Unaffected }\end{array}$ & & $\begin{array}{l}0.03 \\
1.02\end{array}$ & $\begin{array}{l}0 \cdot 21 \\
1 \cdot 19\end{array}$ & $\begin{array}{l}\text { No } \\
\text { No }\end{array}$ \\
\hline
\end{tabular}

*Expressed as the ratio: EMG during acceleration/EMG during periods of no acceleration. Ipsilateral = right sternomastoid during rotation to right or left sternomastoid during rotation to left. Contralateral = right sternomastoid during rotation to the left or left sternomastoid during rotation to the right. 


\section{- Patient 1 느 Normal controls \\ - Patient 2 \\ - Patient $3 \mathrm{~W} / / / /$ ST controls}

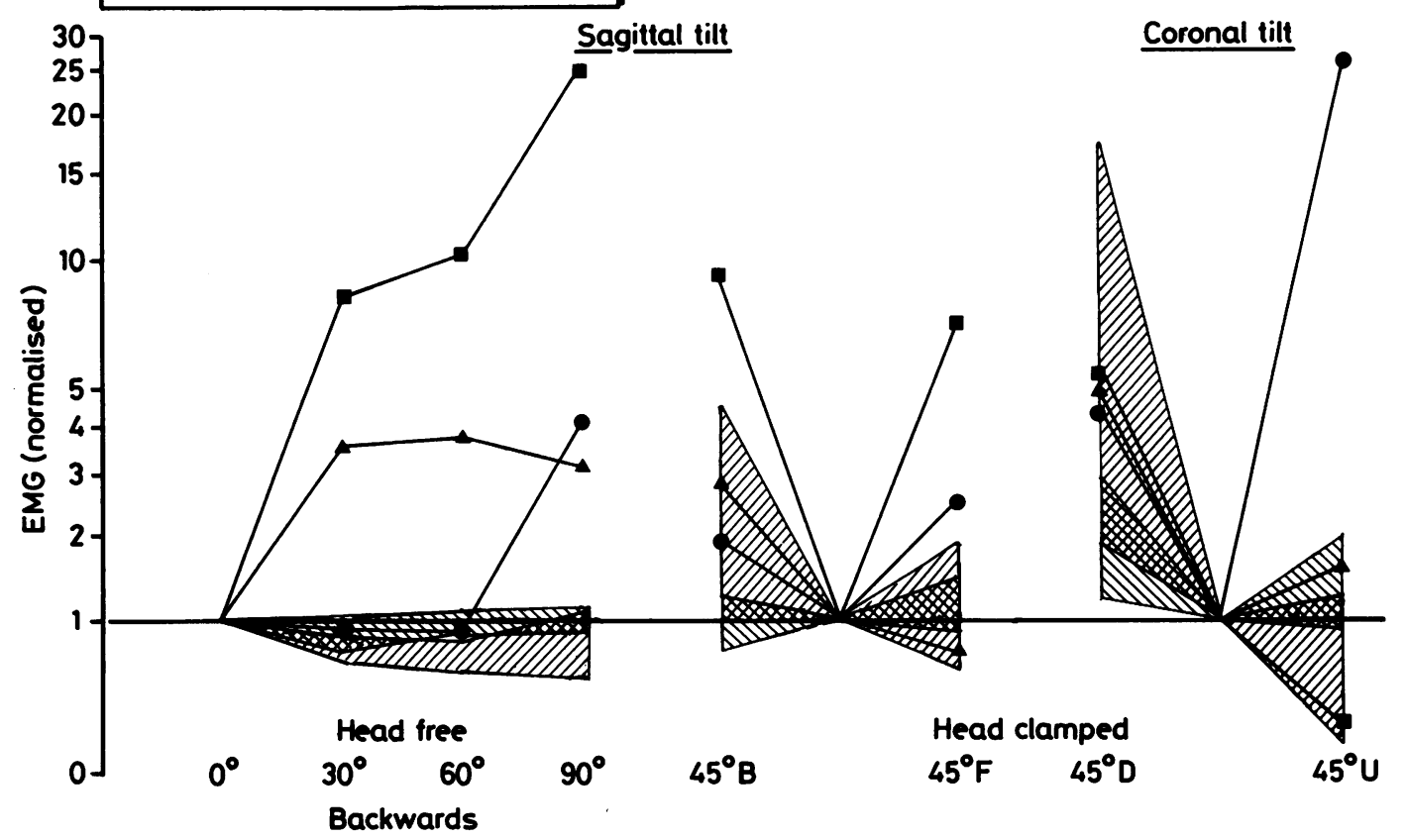

Fig 1 EMG of the more affected sternomastoid in response to tilt backwards $(B)$ forwards $(F)$ side down $(D)$ or side $u p(U)$. Shaded areas represent the interquartile range in the normal and $S T$ control groups. Median values are presented for the VIII-ST patients. EMG was normalised for each subject and test condition so that a value of 1 represents the upright position.
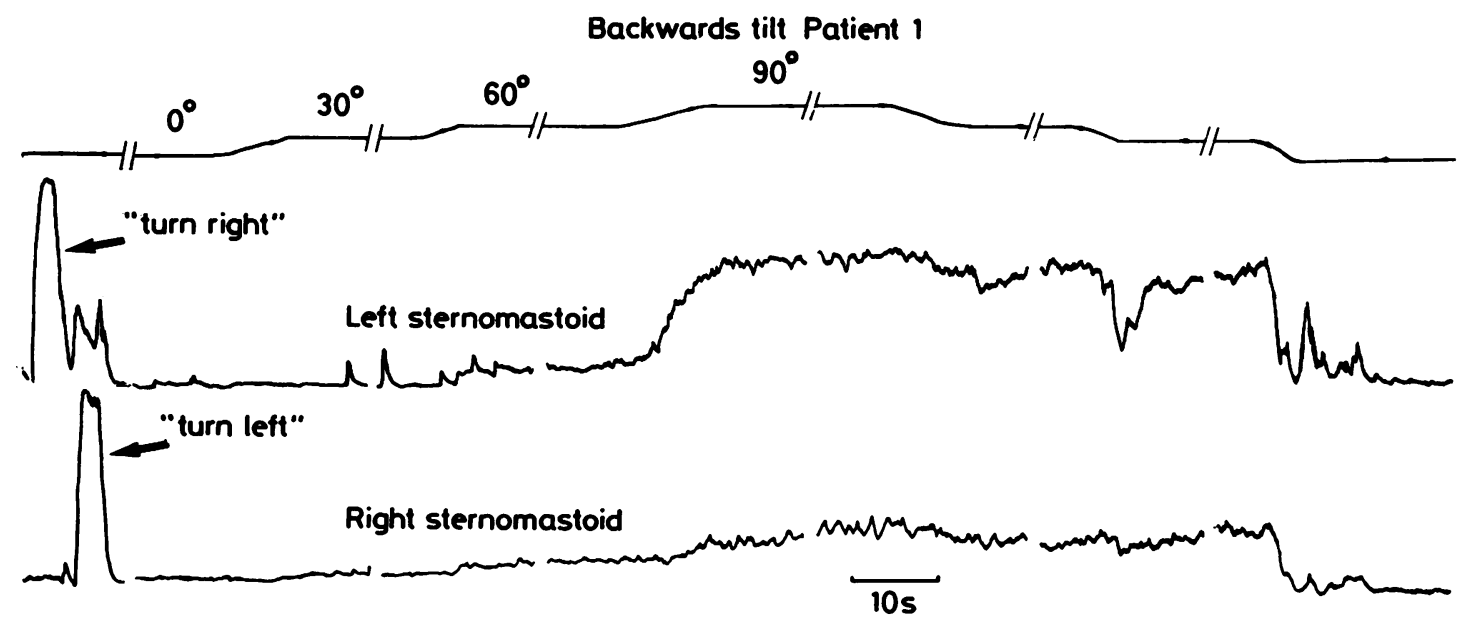

Fig 2 Rectified and integrated EMG in a patient with a left acoustic neuroma removed and ST with chin rotation to the right. The patient was tilted backwards with his head freely resting. "Turn right" and "turn left" are voluntary forced head turns used as calibration. Records interruption, shown with parallel lines, were between 10-40 seconds. 


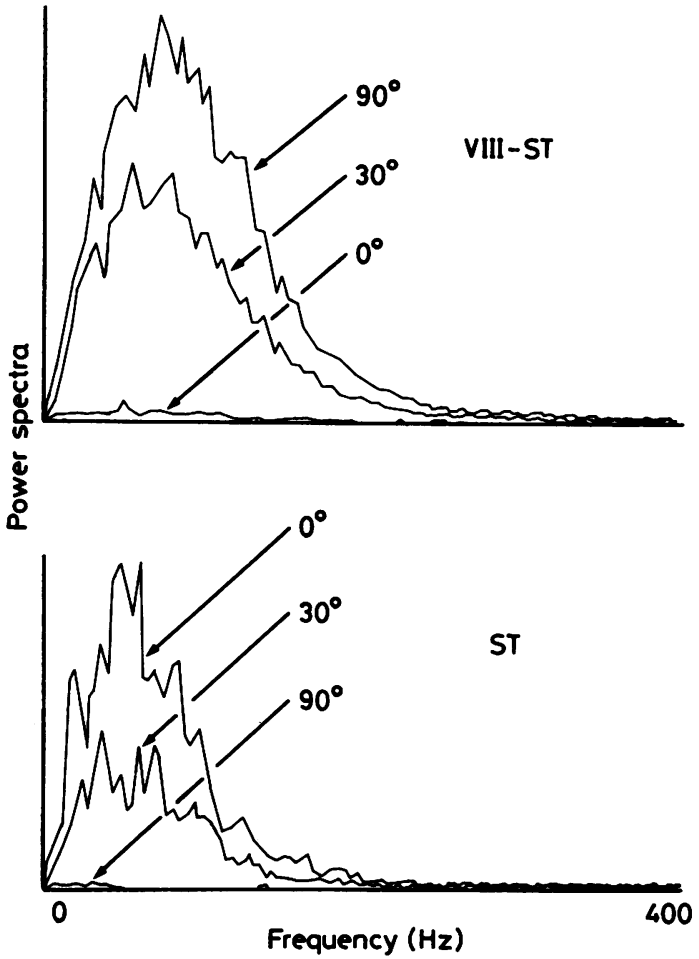

Fig 3 Power spectra of EMG from the more affected muscle in patient 1 and in a ST control patient at various angles of tilt backwards with the head free. Power was measured in $V^{2}$ and normalised to $0^{\circ}$ of tilt.

ticollis have been reportcd. ${ }^{7-10}$ Some of the cases in the literature had irritative labyrinthine lesions with marked fluctuations of the symptoms in whom a precise topographic diagnosis was difficult to establish. In contrast to this, in the present series two of the three patients undoubtedly had unilateral destructive lesions (nerve division in cases 1 and 3 ). The torticollis in these two patients was towards the right in both cases in spite of the nerve section being on the right in one case and the left in the other, arguing strongly against the tempting, but simple view, that unilateral vestibular lesions can produce spasmodic torticollis by virtue of an asymmetric vestibulo-collic reflex. This does not necessarily mean, of course, that the vestibular system and spasmodic torticollis do not influence each other.

The present investigations show that the three VIIIST patients differed in their postural control from the cases of idiopathic spasmodic torticollis and normal subjects. In particular the response of the cervical muscles to backwards tilt with the head free was consistently different in the three groups of subjects studied. In the normal controls this manoeuvre did not modify the resting EMG and in the spasmodic torticollis group either it did not change the activity significantly or reduced it. In the three VIII-ST patients neck EMG was markedly enhanced especially that from the more affected sternomastoid. It is known from animal studies that these effects are probably dependent upon otolith macular activity. Magnus $^{1}$ described static vestibular reflexes in which maximal tonus in the decerebrate preparation occurred in the supine position and minimal tonus while prone. More recent studies have indicated that it is in these positions that macular units reach their maximal and minimal firing frequencies respectively. ${ }^{1314}$ Since the utricular macula is approximately horizontal when the animal is standing this position is also the point of optimal sensitivity, that is maximal change of discharge frequency per angle of head deviation relative to gravity.

It is reasonable to expect that during backward tilt macular discharge will activate both sternomastoids in order to keep the head upright or at least, in the absence of a supporting surface, to keep it aligned with the trunk. Clearly, if one VIII nerve is sectioned, tilt backwards will produce a maximal imbalance of macular input to the CNS since one macula will greatly increase its activity while the other is silent. Such a patient who also has spasmodic torticollis may be reasonably compensated in the upright position because the remaining utricle is in its optimal position for signalling changes of linear acceleration and is discharging at a moderate rate.

The situation is different in the supine position. In these circumstances the utricular macula will be at its maximal firing frequency and minimal sensitivity. Unilateral absence of vestibular function in otherwise neurologically normal subjects does not seem to produce a significant increase in the EMG; in three such patients tested sternomastoid EMG increased by a factor of 1.22 in the muscle contralateral to the vestibular loss and 1.09 in the ipsilateral one (median values) when tilted from 0 to $90^{\circ}$ (unpublished observations). However, in the presence of deranged processing of head/eye position information such as occurs in spasmodic torticollis, this could well lead to a pathological enhancement in the neck EMG discharge. Thus, it is likely that the abnormal tilt/EMG reaction present in the VIII-ST group is due to the unique combination of two different factors: imbalance of peripheral macular signals and perverted central processing of the information concerning head orientation. Evidence for this latter factor stems from two sources. First there is a high incidence of vestibulo-ocular abnormalities as shown in a previous review of patients with spasmodic torticollis. ${ }^{6} \mathrm{Sec}-$ ondly spasmodic torticollis patients are reported to have perverted or exaggerated muscle responses to 
extero-proprioceptive stimuli and semicircular canal stimulation, ${ }^{11} 15$ the latter also being suggested by the rotational experiments in the present study.

In summary, the cases presented here do not indicate that a peripheral labyrinthine disorder can be held directly responsible for the clinical picture of spasmodic torticollis. However, there is some evidence that an VIII nerve lesion can modify, aggravate and perhaps precipitate spasmodic torticollis by inducing further disruption in the processing of sensory information about head position. It follows from this that operations on the vestibular system in idiopathic spasmodic torticollis are unlikely to be therapeutically effective; indeed aggravation of the torticollis might well occur.

AMB was supported by the Brain Research Trust.

\section{References}

1 Magnus R. Korperstellung. Verlag von Julius Springer, Berlin 1924.

2 Brain WR. On the rotated or "cerebellar" posture of the head. Brain 1926;49:61-76.

3 Halmagyi GM, Gresty MA, Gibson WPR. Ocular tilt reaction with peripheral vestibular lesion. Ann Neurol 1978;6:80-3.

4 Uemura T, Cohen B. Effects of vestibular nuclei lesions on vestibulo-ocular reflexes and posture in monkeys. Acta Otolaryngol (Stockh.) Supplement 315:1973.
5 Herz E, Hoefer PFA. Spasmodic Torticollis. Arch Neurol Psychiatry 1949;61:129-36.

6 Bronstein AM, Rudge P. Vestibular involvement in spasmodic torticollis. J Neurol Neurosurg Psychiatry 1986;49:290-5.

7 Barre J-A. Le Torticolis Spasmodique. Rev Neurol (Paris) 1929;1;:984-1013.

8 Barre J-A, Guillaume J. Torticollis spasmodique; troubles vestibulaires unilateraux. Remarques cliniques et chirugicales. Rev Neurol (Paris) 1930;1:485-7.

9 Hyndman OR. Torticollis Spastica. Arch Otolaryngol 1939;29:827-38.

10 Svien HJ, Cody DTR. Treatment of spasmodic torticollis by suppression of labyrinthine activity: report of a case. Mayo Clin Proc 1969;44:825-7.

11 Denny-Brown D. Clinical symptomatology of diseases of the basal ganglia. In: Vinken PJ, Bruyn GW, eds. Handbook of Clinical Neurology Vol 6. Amsterdam: North Holland Publishing Co, 1968:133-9.

12 Burke RE, Fahn S. Chlorpromazine methiodide acts at the vestibular nuclear complex to induce barrel rotation in the rat. Brain Res 1983;288:273-81.

13 Loe PR, Tomko DL, Werner G. The neural signal of angular head position in primary afferent vestibular nerve axons. J Physiol (Lond) 1973;230:29-50.

14 Fernandez C, Goldberg JM. Physiology of peripheral neurons innervating otolith organs of the squirrel monkey. I. Response to static tilts and to longduration centrifugal force. $J$ Neurophysiol 1976;39:970-84.

15 Podivinsky F. Torticollis. In: Vinken PJ, Bruyn GW. Handbook of Clinical Neurology Vol 6. Amsterdam: North Holland Publishing Co, 1968:567-603. 